\title{
STARTING POINT SELECTION IN GROUPING DESIGN METHOD FOR LITHOGRAPHIC OBJECTIVES
}

\author{
N.D. Zoric a, I.G. Smirnova ${ }^{a}$, S. Georgiou ${ }^{b}$
}

a ITMO University, Saint Petersburg, 197101, Russian Federation

b Athens University of Economics and Business, Athens, 10431, Greece

Corresponding author: nenadnex@gmail.com

\section{Article info}

Received 27.06.19, accepted 30.07.19

Article in English

For citation: Zoric N.D., Smirnova I.G., Georgiou S. Starting point selection in grouping design method for lithographic objectives. Scientific and Technical Journal of Information Technologies, Mechanics and Optics, 2019, vol. 19, no. 5, pp. 790-800 (in English). doi: $10.17586 / 2226-1494-2019-19-5-790-800$

\section{Abstract}

This work aims on method development for obtaining initial designs for ultraviolet (UV) and deep-ultraviolet (DUV) objectives through global search algorithm. We studied a global search based algorithm tending to obtain the feasible local minima of lens design landscape. One of the major challenges of our work is writing macro input related to a number of lenses, the length of objective, and glass material. The obtained results show the main advantages and efficiency of the design approach based on the global search algorithm. As an output, we developed a method and criteria for successful selection of the starting point of micro-lithographic objectives.

\section{Keywords}

lithography, optical design, projection lens, DUV, UV, global search algorithm, starting point

Acknowledgements

The research leading to these results has received funding from the People Programme (Marie Curie Actions) of the European Union's Seventh Framework Programme (FP7/2007-2013) under REA grant agreement no. PITN-GA-2013-608082 "ADOPSYS".

\section{ВЫБОР ИСХОДНОЙ ОПТИЧЕСКОЙ СХЕМЫ МЕТОДА ГРУППОВОГО ПРОЕКТИРОВАНИЯ ЛИТОГРАФИЧЕСКИХ ОБЪЕКТИВОВ}

\author{
Н.Д. Зорич ${ }^{\mathrm{a}}$ И.Г. Смирнова ${ }^{\mathrm{a}}$, С. Георгиу
}

а Университет ИТМО, Санкт-Петербург, 197101, Российская Федерация

b Афинский университет экономики и бизнеса, Афины, 10431, Греция

Адрес для переписки: nenadnex@gmail.com

Информация о статье

Поступила в редакцию 27.06.19, принята к печати 30.07.19

Язык статьи - английский

Ссылка для цитирования: Зорич Н.Д., Смирнова И.Г., Георгиу С. Выбор исходной оптической схемы метода группового проектирования литографических объективов // Научно-технический вестник информационных технологий, механики и оптики. 2019. Т. 19. № 5. С. 790-800 (на англ. яз.). doi: 10.17586/2226-1494-2019-19-5-790-800

\section{Аннотация}

Целью настоящей работы является разработка метода получения исходных оптических схем для литографических объективов ультрафиолетового (UV) и глубокого ультрафиолетового диапазонов (DUV) на основе алгоритма глобального поиска. Исследованы возможности алгоритма глобального поиска для получения локальных минимумов в пространстве оценочной функции проектирования литографических объективов. Среди основных задач представленной работы определение закономерностей для параметрических и входных данных макроса, связанных с количеством линз, длиной объектива и материалом оптических стекол. Полученные результаты демонстрируют эффективность и основные достоинства метода, основанного на алгоритме глобального поиска. Результатом работы является разработанный метод и критерии успешного выбора исходных оптических схем для микролитографических объективов. 


\section{Благодарности}

Работа выполнена при поддержке Реople Programme (Marie Curie Actions) Седьмая рамочная программа Европейского Союза (FP7/2007-2013) REA грант. Соглашение № PITN-GA-2013-608082 «ADOPSYS».

\section{Introduction}

Over the last six decades, the available computing power has increased significantly. New processing power boosted the interest in development of global optimization methods that can overcome the barriers of merit function around the local minima [1] and provide a more efficient search for a global minimum. Different algorithms were developed and applied in global optimization approaches, such as: simulation of "annealing", neural networks, fuzzy algorithms, particle swarm algorithm [2].

For optical models with smaller complexity (less than 10 lenses), the existing global optimization algorithms have proven as valuable tools in finding a successful solution among the many local minima, in the landscape of merit function. However, as the number of variables grows, even local optimization begins to be an extremely time-consuming process, and it becomes increasingly difficult to apply such a method in design.

One approach that can be successfully used in design of complex systems, such as lithographic objectives, is splitting the total system into more subsystems. In this way, the reduced number of variables in the subsystems simplifies the design of complex lithographic lens, while increasing the applicability of global search algorithms.

Prior work reveals several novel global search algorithms, such as DSearch in Synopsys, OSD (Optical System Design), or Global Synthesis in CODE V lens design software, allowing the optical designers to have more efficient search for a promising starting point of objective. However, the applicability and effectiveness of these algorithms are under research for the development of global optimization strategies.

The grouping method in design of lithographic objectives was explained and studied by Ulrich and Dodoc [3]. The authors synthesized deep-ultraviolet (DUV) objectives through the design of separate optical modules and well-known combinations of microscope objectives [4]. Grouping design allocates the complexity of the whole system design to each of the lens groups increasing the design efficiency as proven by Cao Z [5].

While the traditional design methods lead to designs with very complex theoretical analysis of separate modules which is not inevitable, our modified grouping design method relies on effectiveness of global search algorithm and entirely automated lens design. Additionally, this is a novel design approach in complex lens design which can come up with feasable starting points quickly and effectively. The lens groups are assembled by a global optimization algorithm according to proposed method of starting point construction and selection. The key advantage of our design approach is the generation of significantly more starting points of micro-lithographic objective, that can be analyzed with further optimization leading to the best solution, in less time.

\section{Density maps of starting points for $365 \mathrm{~nm}$}

A shortcoming of developed method is that we first generate two starting points of photo-objectives in the UV spectrum with maximum of 15 lenses [6]. More specifically, we build macros in Synopsys OSD lens design software and run global search of two separate modules. DSearch (Design Search) function in the SYNOPSYS, OSD, lens design program is implemented in one of the novel effective binary search algorithms. It proved its efficiency in searching for starting points of photo objectives with moderate complexity. Since the DSearch algorithm [7] receives commands by macro lines, adjustable inputs — parameters and requests must be calculated and adjusted.

DSEARCH uses a search method based on a binary number, each bit corresponding to a lens element, the power of the element either positive or negative according to the value of that bit. Thus, a four-element lens created with number 0000 would have all negative elements, while 0001 would produce a lens with one positive element [6]. Consequently, the distribution of optical power is the challenging task to be controlled by an algorithm. Additionally, there are commands (requests) which could also reduce optical path difference errors (OPD), a feature useful for lenses whose modulation transfer function (MTF) must be close to the diffraction limit. The main challenge of DSearch algorithm is to determine the parameters which define the shape and number of lenses as part of the lithographic objective. Our main task is to build a macro which will generate the starting designs with logical optical scheme and good local minima of merit function [8].

In order to calculate the object parameters [9], needed to algorithm command OBB U W Y ( $W$ - field of view and $Y$ - marginal ray height), we firstly examine the reasonable focal length of the rear part with $F N 1.2$. If we assume a focal length $f-150 \mathrm{~mm}$, we obtain OBB 03.7962 .5 , but for $f-100 \mathrm{~mm}$ we get OBB 05.69 41.7. Consequently, this object parameters influence the shape of starting point and performance of image point. Fig. 1 illustrates the difference between the starting points with different infinite object parameters having the same $F$ number. Logically, we tend to have smaller FOV $(W)$ which allows smaller optical aberrations, but, on the other hand, the shape of optical scheme and ray tracing should be considered. We have chosen $f-100 \mathrm{~mm}$ as reasonable input for marginal ray height $-41 \mathrm{~mm}$ with acceptable small field of view. 


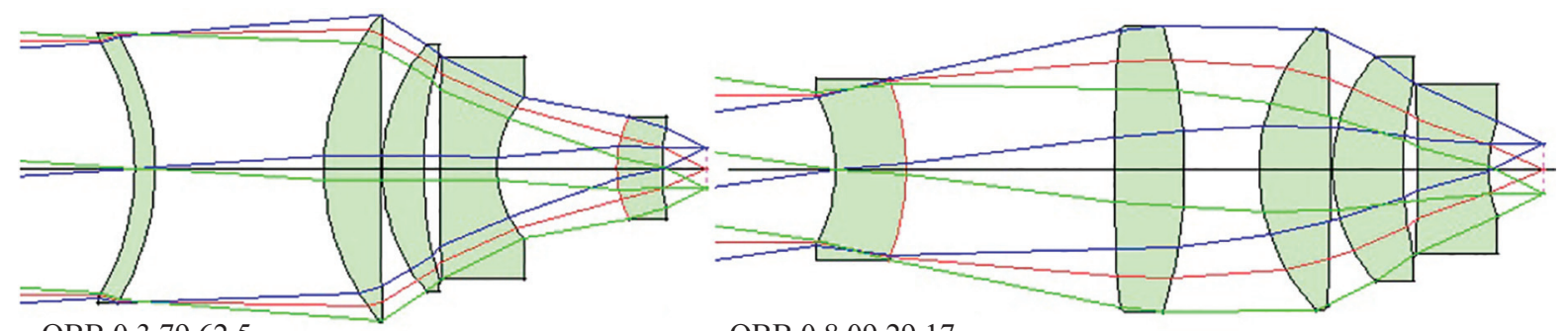

OBB 03.7962 .5

OBB 08.0929 .17
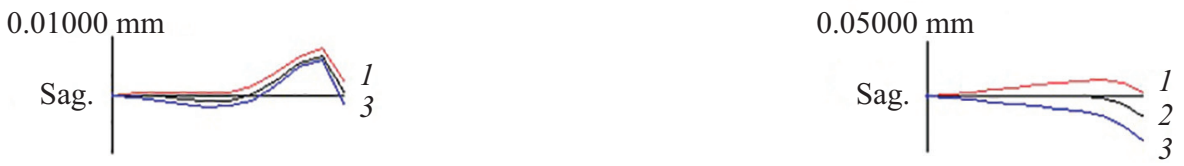

Fig. 1. Starting points of rear part with different object parameters

The technical characteristics of separate parts are derived from the UV lithographic objective for $365 \mathrm{~nm}$ [9]. The most challenging parameters of macro input, that need to be adjusted and determined, are:

— the field of view (FOV);

- a number of lenses;

— the length of objective;

- glass material.

The developed design method consists of few steps and stages which should formalize the writing of macro input.

- In Step 1, we calculate the characteristics of both parts at object side, field of view and semi-aperture. This is the easier part of adjusting object parameters of macro by assuming a point where the two parts of UV objective to be connected.

- In Step 2, we run a series of simulations that sweep through the possibilities of starting designs adjusting the number of lenses and total length of two optical modules. Ideally, these simulations by DSearch should determine a set of input parameters where the transversal aberrations, over the entire FOV, will be less than $0.005 \mathrm{~mm}$ in order to have fairly corrected aberrations close to diffraction limit.

- In Step 3, we combine the separate optical modules in an optical scheme obtaining starting point of lithographic objective for further optimization.

In the previous paper [9] we described the calculations of lens characteristics required for macro input parameters from Step 1 .

The parts of the macro with bold lines (the parameters), that are written and corrected after simulations, can be seen above Fig. 2. When designing the UV lithographic objective for $365 \mathrm{~nm}$, available glass materials of I-Line catalogue is a limitation [10]. Since the rear part of lithographic objective on the image side is more complex designed to create high NA, we carried out a study to design this part first. As the first approach, we assigned the glass material of positive and negative lenses in a rear optical module with 6 lenses. More specifically, we used two variants of this approach in sequence, where we varied one parameter - lens length at a time by a fixed number of lenses and quit when no more changes were helpful.

\begin{tabular}{|c|c|}
\hline \multicolumn{2}{|l|}{ ID LITHO REAR } \\
\hline OBB 05.6941 .667 & FNUM 1.210 \\
\hline UNI MM & BACK 22100 \\
\hline WAVL .368 .365.362 & \\
\hline END & \\
\hline GOALS & \\
\hline ELEMENTS 6; & \\
\hline
\end{tabular}

\section{GLASS POS; define glass O PBM2Y GLASS NEG; define glass O S-FPL53}

Obviously, this approach was not successful because of the following reasons: two glass materials were not enough to get the effective achromatization of I-Line part of the objective; the use of two glass materials minimized the combinations of negative and positive lenses via the global search algorithm; only six lenses were not sufficient to reach transversal aberrations even less than $0.01 \mathrm{~mm}$. The resulting design is presented in Fig. 2 with 6 lenses.

As for the second approach, we have erased the lines which determine the glass material in macro (above Fig. 2), allowing that glass models vary in a total specter of refractive index N. DSearch has generated a few combinations with transversal aberrations of $0.005 \mathrm{~mm}$. The trial with seven lenses has shown better results where the few starting points have reached the aberrations of $0.005 \mathrm{~mm}$ for the total length of $280 \mathrm{~mm}$. This was promising approach with 7 and 8 lenses in a rear optical module until the moment we started replacing glass model starting point with real glass from I-Line catalogue (Fig. 2). Since our glass model was in total specter of visible light, refractive indexes were too high for glass materials in the area where the I-Line glasses are located. The transversal 
aberrations of rear optical module were significantly increased (up to $0.02 \mathrm{~mm}$ ) after substitution by the real glass material from the I-Line catalogue [11].
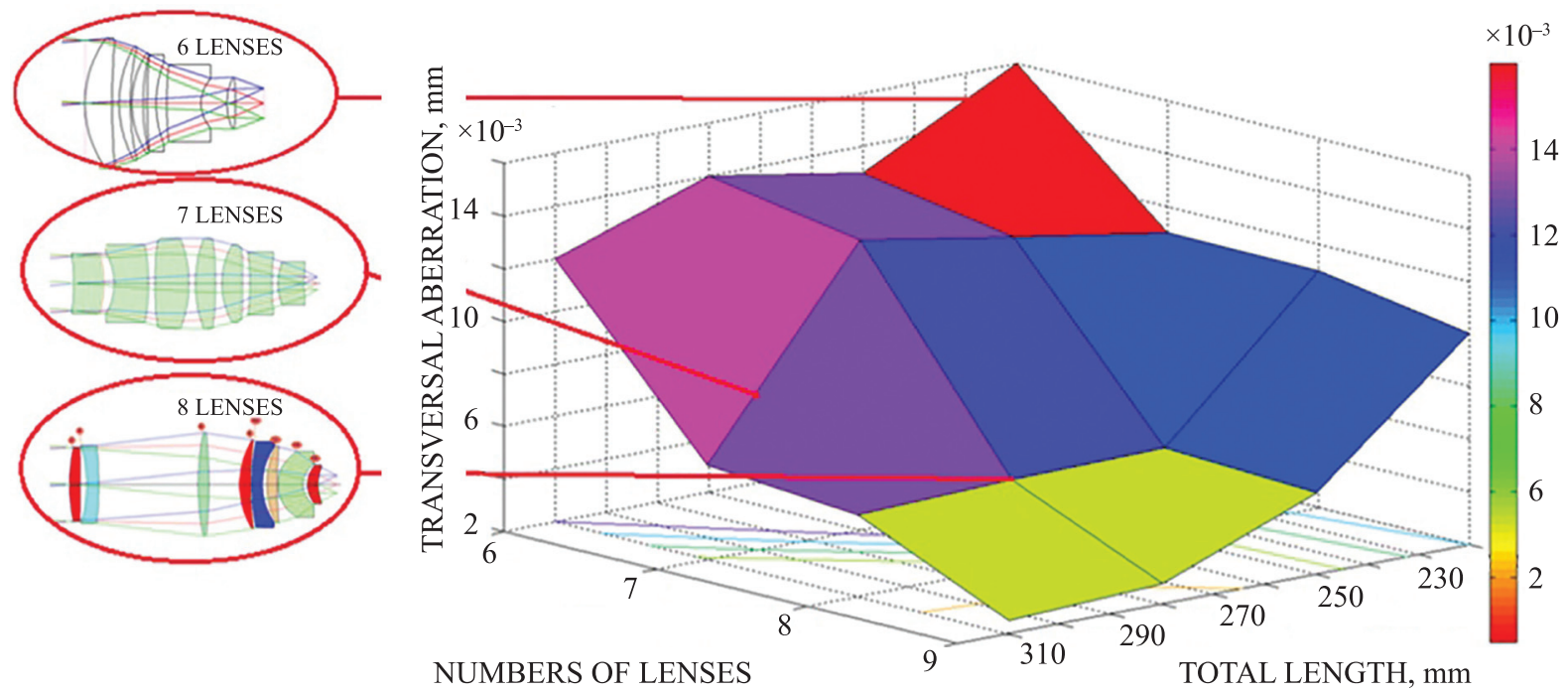

Fig. 2. 3D map of starting points for rear part

We concluded that the glass model must be limited in specter of I-Line, at initial stage. In macro we constrained the region of the glass map to that $N$ (refractive index) in which glasses were suitable for the I-Line. The algorithm accepts input parameters defining this region, as below CBOUNDS (crown limit) 1.88 6.43 1.49 83.55, which describes a line from the points $N=1.88, V=6.43$ to the point of glass model $N=1.49, V=83.55$. These constraints have given us more flexibility in a real design of rear optical module for UV lithographic objective.

SPECIAL PANT

CBOUNDS 1.88 6.43 1.49 83.55

FBOUNDS 1.92 22.16 1.50 62.67

CUL 1.6;

FUL 1.6; upper crown limit for refractive index upper flint limit for refractive index

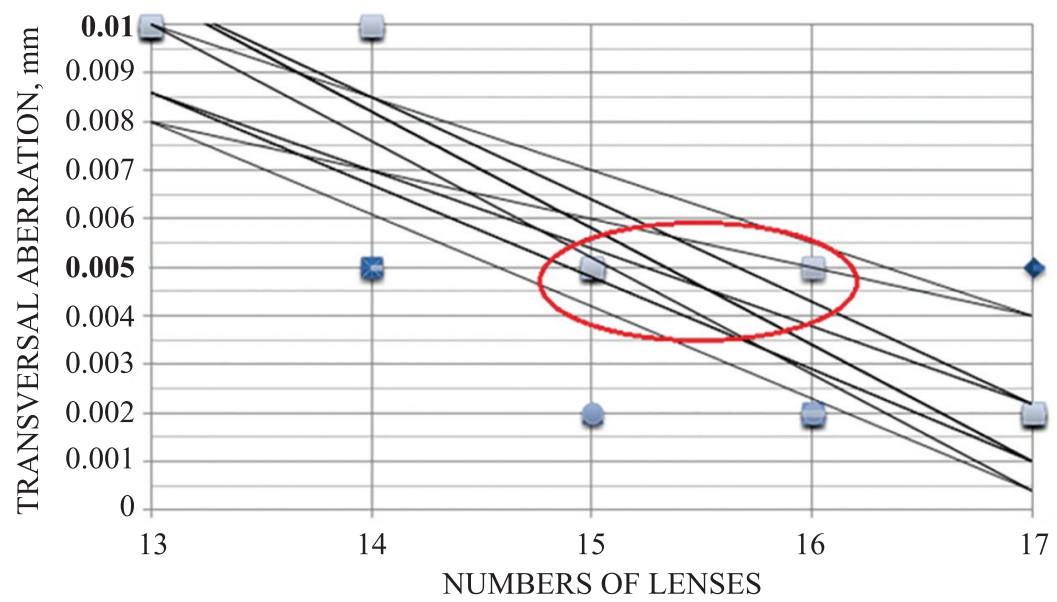

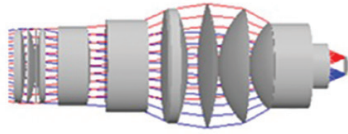

11 LENSES $330 \mathrm{~mm}$

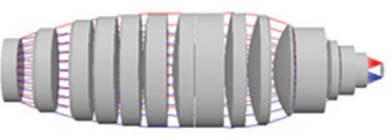

15 LENSES $450 \mathrm{~mm}$

Fig. 3. Selecting starting point of rear part by density map of generated starting points

Particularly, in this way we expect that all lenses starting points will keep the refractive indexes close to the existing glasses from I-Line catalogue. Thus, if the refractive index is limited the new starting points automatically tend to have more lenses (more optical power). This can be automatically noticed when we run again simulations with 8 lenses. Even, the next generated group of starting points having 10 and 12 lenses mostly had transversal aberrations higher than $0.01 \mathrm{~mm}$. Fig. 3 shows the density map of 50 generated starting points. On every vertical line of density map (input parameter - number of lenses) 10 starting points are plotted, represented by their transversal aberrations (dots markers). Due to the same values ( 0.005 or 0.002$)$, there is a noticeable overlapping on the map. A majority of starting points is forming an area of high density connected by diagonal lines. Our main task here is to pick up the promising starting points and to select the one which suits the specific criteria. 
The promising starting points are those which possess the transversal aberrations over all field of 0.005 $\mathrm{mm}$ or less. As it can be seen in Fig. 3, the most of the starting points with $0.005 \mathrm{~mm}$ of transversal aberrations are placed in region from 15 to 16 lenses by applied constraints and macro input. As we increase the number of lenses, we have proportionally to increase the length of the optical scheme. Experimentally concluded, it should be added about $30 \mathrm{~mm}$ for every inserted new lens. Note that in this map area the few starting points having $0.002 \mathrm{~mm}$ of transversal aberrations appeared.

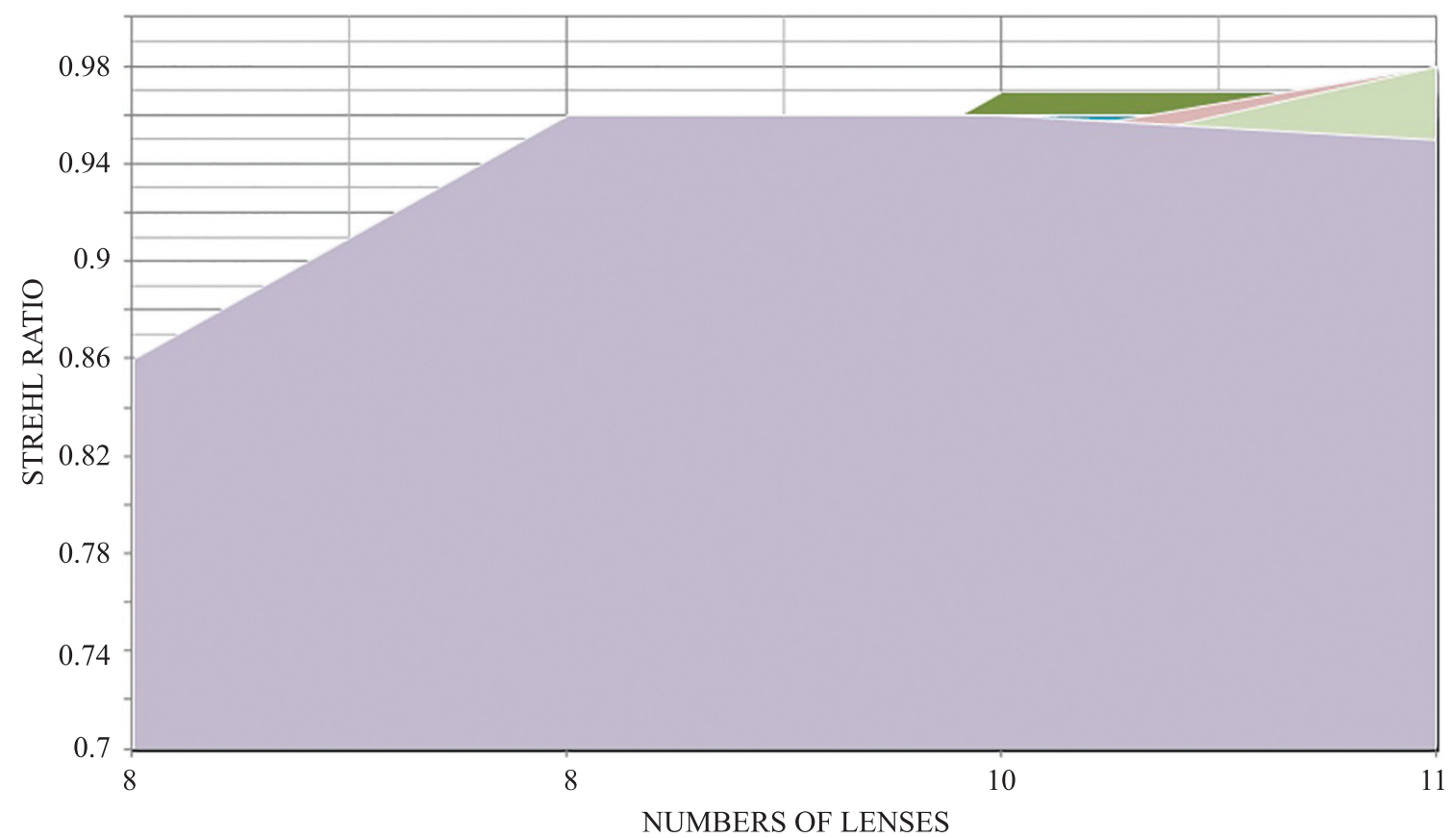

Fig. 4. Density map of starting points for front part presented by Strehl ratio

At this point we select the starting points consisting of 15 lenses (Fig. 3) placed in area of solution - majority of starting points of $0.005 \mathrm{~mm}$ transversal aberrations (marked by red line), and, secondly, we look for the one with the best image quality (comparing RMS wave front aberrations). The efficiency of this approach in lens selection is proved by many attempts in choosing the starting points with smaller number of lenses and it is closely related to Rayleigh criterion [12].

When designing the second part (front module), we pay attention on Strehl ratio since the F number is 6 , a condition which simplifies design task. Again, we must build a macro which will generate the starting designs with logical optical scheme and good local minima of merit function. Down below the part of macro is shown where we define the characteristics of the front part.

ID LITHO FRONT

OBB 0 5.69 41.667;

UNI MM;

WAVL .368 .365 .362;

END

GOALS ;

ELEMENTS 10;

TOTL 330 0.1;

FNUM 610 ;

BACK 150 100; object parameters, 0 - paraxial marginal ray angle, 5.69 - field angle of object, 41.667 - axial marginal ray height on surface 1

declare wavelengths

define design goals

number of lenses

length of front part

define Field number -6 , weight -10

define back focus -150 , weight -100

As you can notice, the definition of object is the same OBB 05.6941 .667 for the front optical module (Fig. 5) since, firstly, we design the reversed front part of the objective [8]. Whole process of obtaining the starting point for the front part is very similar to the rear part of lithographic objective. The main difference that we observe in this case is that the criterion on the density map of starting points of the Strehl ratio is larger than 0.9 (Fig. 4). Adjusting the parameters of macros (the number of lenses and length), we obtained a few starting points with 0.9 Strehl having 9 lenses, and many with 10 lenses. Different colors of density map represent areas of relatively similar values of Strehl ratio. The largest area shows that the majority of obtained starting points is placed between 0.96 and 0.86 . As a matter of fact, this selection criterion for the front optical module ensures smooth compensation of optical aberrations later, when we connect both parts (10 plus 15 lenses), and re-optimize the lithographic objective 
up to diffraction limit. For this proof-of principle work, we must reach the point where we connect the both parts of starting points and re-optimize for the first time.

Table 1. Optical characteristics of obtained starting point for UV lithographic objective

\begin{tabular}{|l|l|}
\hline Wavelength & $365 \mathrm{~nm}$ \\
\hline F-number & 1.2 \\
\hline Image height & $20 \mathrm{~mm}$ \\
\hline Magnification & -0.2 \\
\hline Total track length & $660 \mathrm{~mm}$ \\
\hline Front working distance & $150 \mathrm{~mm}$ \\
\hline Linear distortion & less than $0.5 \mu \mathrm{m}$ \\
\hline
\end{tabular}

Fig. 5 illustrates the starting design of UV lithographic objective with 0.002 transversal aberrations immediately after few re-optimization of entire starting point (25 lenses). During the optimization with 131 optimization variables (all variables including glass models), an aperture stop is floating in lithographic objective which determines the telecentric object (TCO). Distortion and telecentricity on image side are controlled by requests within optimization macro. At this step the Strehl ratio is more than 0.99 for over entire field at $365 \mathrm{~nm}$, while distortion is less than $1 \%$. The characteristics of obtained starting point are presented in Table 1.

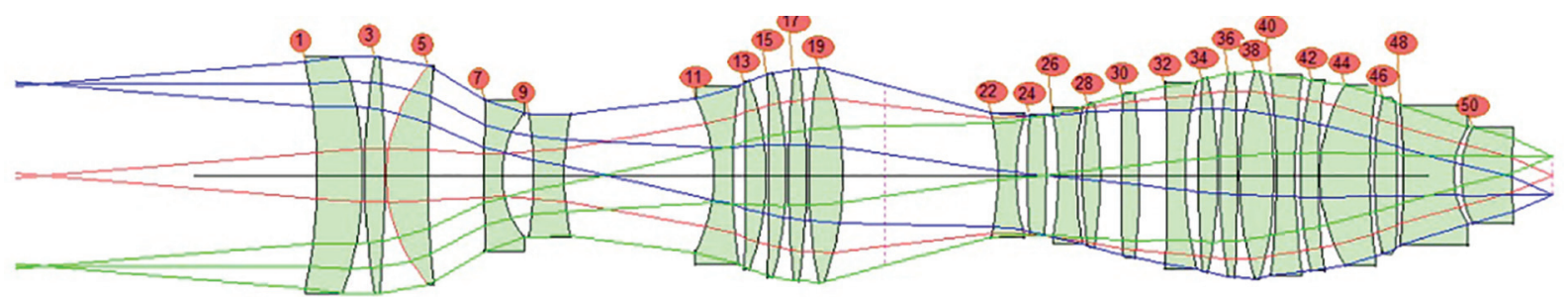

front optical module FNo 6

real optical modul FN 1.2

Tan.
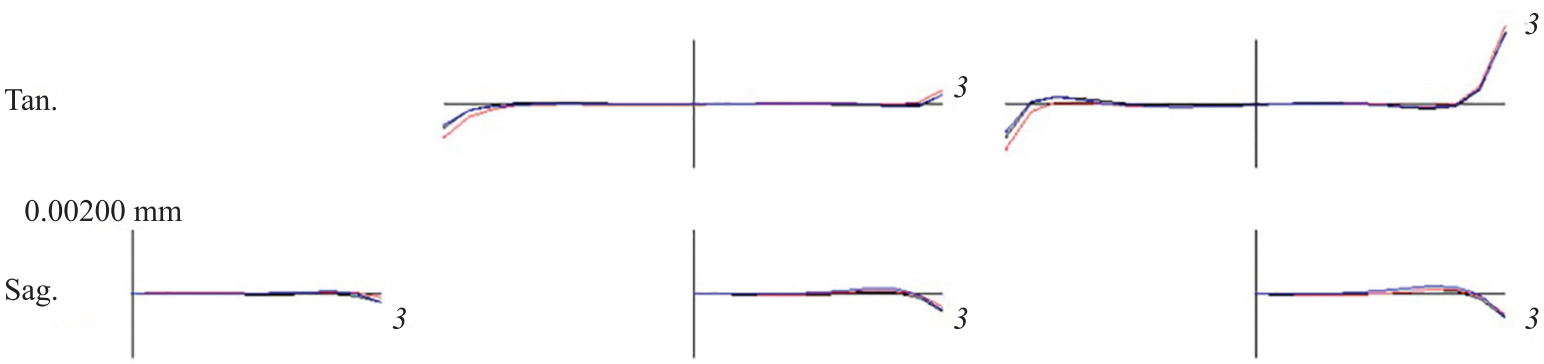

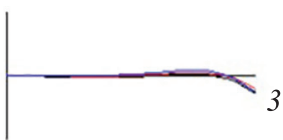

0.75000

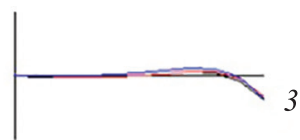

1.00000

TRANSVERSE ABER

0.00000 REL. FIELD

Fig. 5. Starting point of UV lithographic objective with glass model after optimization

However, since we are simulating the glass model, we expect that MTF will drop off after replacing the glass model by real glass. Therefore, it is useful to have the MTF of glass model much closer to the ideal system [12, 13]. Alternatively, we might get the starting point of lithographic objective which doesn't possess enough potential to reach diffraction limit. That can possibly be improved further by adding more lenses, or applying additional global optimization [14].

\section{Density maps of starting points for $248 \mathrm{~nm}$}

Design approach for lithographic objective for $365 \mathrm{~nm}[8,15]$ has been adjusted to design of deep-ultraviolet lithographic objective for $248 \mathrm{~nm}$. By the same technique, we calculate and set up the parameters of macro which determine the characteristics of the object (OBB macro line) and which define the shape of objective. The main difference is that we are assigning the real glass ( $\mathrm{SiO} 2)$ directly in DSearch macro instead of glass model. This makes the task of the algorithm far more challenging. More specifically, in this design we do not have chromatical aberrations, but only the one refractive index which decreases the number of variables in global search.

Beside these conditions, DUV projection lens has numerical aperture (NA) of 0.6 which gives F number of DUV lithographic objective, on image side (1) (the rear part) 


$$
F N i=\frac{1}{2 N A}=0.84
$$

while we are getting the F number on object side (2) (the front part) by multiplying with magnification M,

$$
F N o=M x F N i=4 x F N i=3.36 \text {. }
$$

Obviously, in this design, the problem complexity is influenced by relatively smaller $F N$ and limited variables of glass material which are the input parameters of global search. Once we choose the focal length $f_{1}$ of the rear part (image side), in order to calculate the marginal ray height and FOV, we are ready to build a first version of macro [16]. By the formula for nominal diameter $D N(3)$, we are calculating marginal ray height $Y(4)$ as

$$
\begin{aligned}
& D N=\frac{f_{1}}{F N}=\frac{120}{0.84}=142.86 \\
& Y=\frac{D N}{2}=\frac{142.86}{2}=71.43 .
\end{aligned}
$$

The equitation for field of view (5) gives

$$
w=\arctan \left(\frac{y^{\prime}}{f_{1}}\right)=6.18,
$$

where $y^{\prime}$ is the image height of $13 \mathrm{~mm}$. Since we want to adjust properly input parameters investigating the computing power of DSearch alghoritm, we first try to design the front part of DUV objective with larger $F$ number of 3.36 .

ID DUV FRONT
OBB 0 6.18 71.4;
UNI MM;
WAVL .248;
END
GOALS;
ELEMENTS 15;
TOTL 800 0.1;
FNUM 3.36 10;
BACK 95 100;
GLASS POS;
U FUSILICA;
GLASS NEG;
U FUSILICA;

\author{
infinite object parameters \\ units in $\mathrm{mm}$ \\ working wavelength \\ design goals \\ number of lenses \\ length of objective $800 \mathrm{~mm}$ \\ field number 3.36 \\ back focus 95 \\ define glass for positive power lenses \\ Fusilica glass material from unusual catalogue \\ define glass for negative power lenses
}

The part of written macro which define characteristics of starting point is shown above. We tend to obtain good Strehl ratio by assuming the number of lenses and length of the front part. As expected, after few simulations with various parameters, we verified that the design task is very challenging. In more detail, we were trying various lengths of objective with 12 and 15 lenses; assuming that 15 lenses should be enough for the first part of objective.

We additionally performed some simulations with various (low and high) $F$ numbers to examine the potential of this case and macro parameters. Although, we got slightly better Strehl ratio with higher F number, a decision has been taken to choose focal length of $120 \mathrm{~mm}$ for OBB object parameters. Since the Strehl ratio is smaller than 0.5 in all generated starting points, we decide to introduce lower criteria for selecting starting points of the front part. We select the starting points which posse $0.005 \mathrm{~mm}$ transversal aberration (red line on Fig. 6) assuming that could have enough potential (optimization variables).

Density map of starting points (Fig. 6) presents the dependence of transversal aberrations from the length of objective. The diagonals merge the data points with higher density. For instance, the data point with $800 \mathrm{~mm}$ length, 0.005 represents 2 starting points, but data point with $800 \mathrm{~mm}$ length, 0.01 represents 8 starting points. We see that relatively large length of $800 \mathrm{~mm}$ generates a few starting points of $0.005 \mathrm{~mm}$. Next, we select the most promising one (Fig. 7) by shape despite its unusual length.

For the rear part, we tried to generate efficiently the starting points with length smaller than $500 \mathrm{~mm}$, in order to keep the total track of objective close to $1000 \mathrm{~mm}$. After many simulations and attempts to adjust parameters of the algorithm, we obtained the starting points having 15 lenses with $0.05 \mathrm{~mm}$ transversal aberrations as the best results for the rear part. Such a low efficiency of global search is a consequence of the fact that we have relatively small $F$ number of 0.84 and many boundaries [17]. One of directions how to improve resulting design further is adding more lenses. Nevertheless, we connect both parts of DUV lithographic objective and run local optimization to examine the potential of starting point with 30 lenses. After few re-optimizations using all 122 available variables 
(60 radiuses +62 thickness), the resulting DUV lens shows that starting point does not have enough potential for approximate diffraction-limited system, although MTF is very close to diffraction limit (Fig. 7).

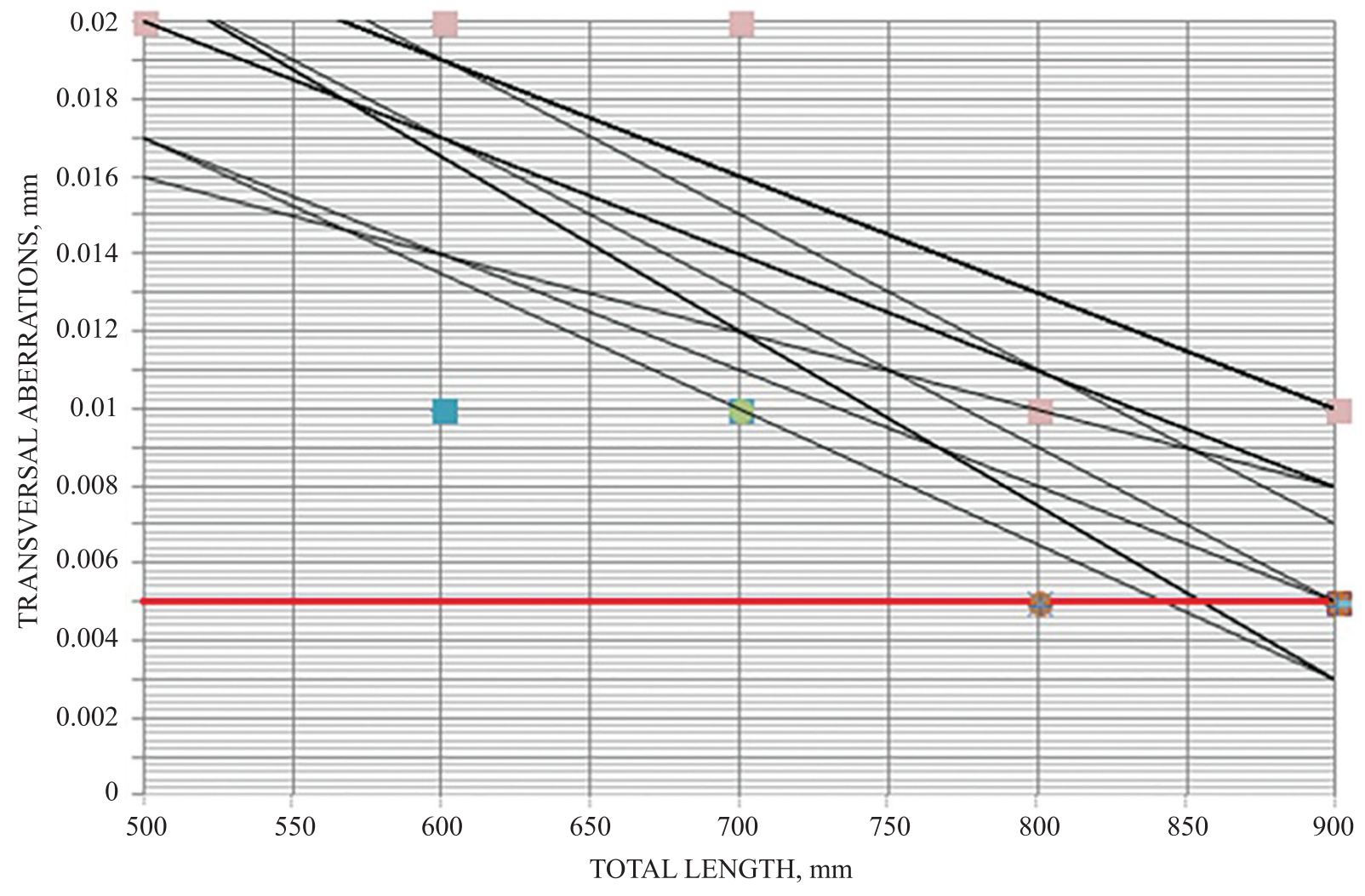

Fig. 6. Density map of starting points presented by transversal aberrations

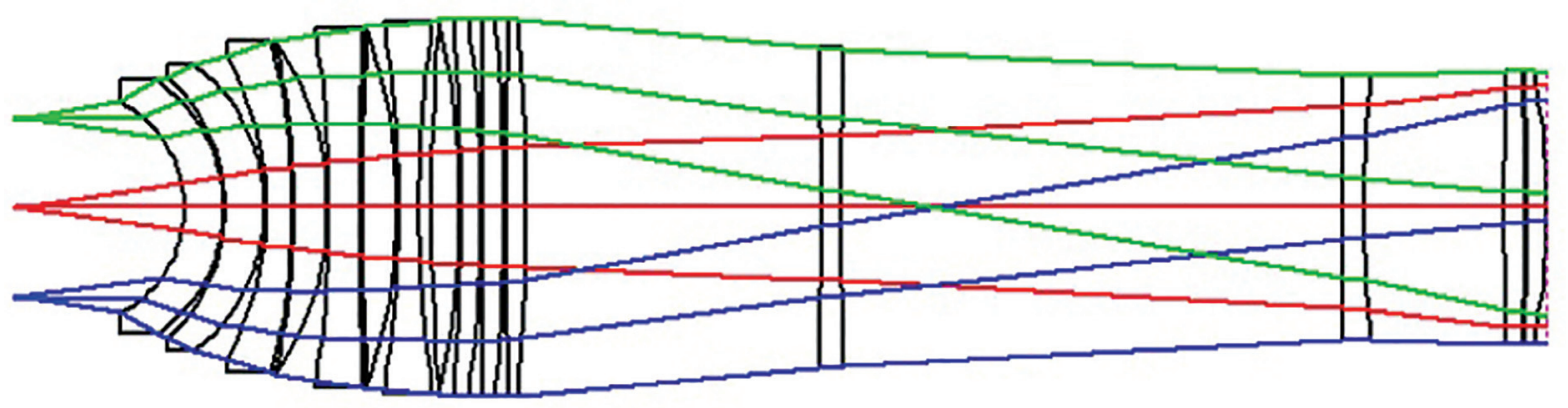

$0.00500 \mathrm{~mm}$

WAVELENGTH, uM

0.2480000

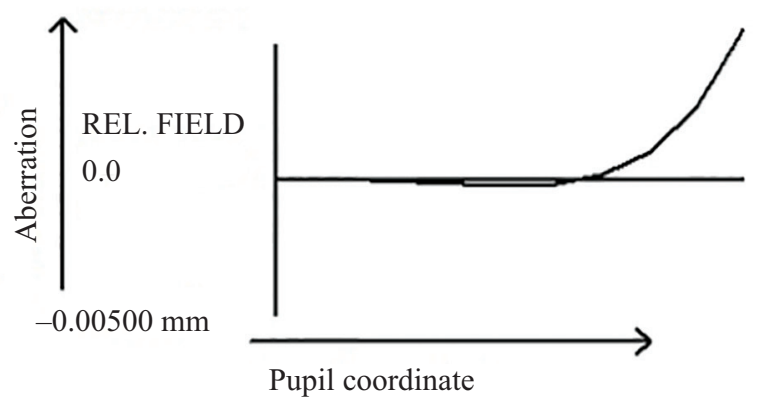

Fig. 7. Starting point of front part with transversal aberration

We are trapped in a poor local minimum due to many optical aberrations where the most critical ones are the Petzval curvature and distortion [18]. MTF presented in Fig. 8 indicates that potential of starting point must be improved by introducing more variables. The obtained results could be affected by selected initial parameters starting from focal length of $120 \mathrm{~mm}$, either by criteria for selecting the starting point for DUV projection lens (the number of lenses). This resulting lens proves that the criterion for selecting the starting point for UV lithographic 
objective (Strehl ratio above 0.9 for front part and transversal aberration of $0.005 \mathrm{~mm}$ for rear part) is more convenient and more accurate in obtaining the feasible starting point with sufficient number of variables.

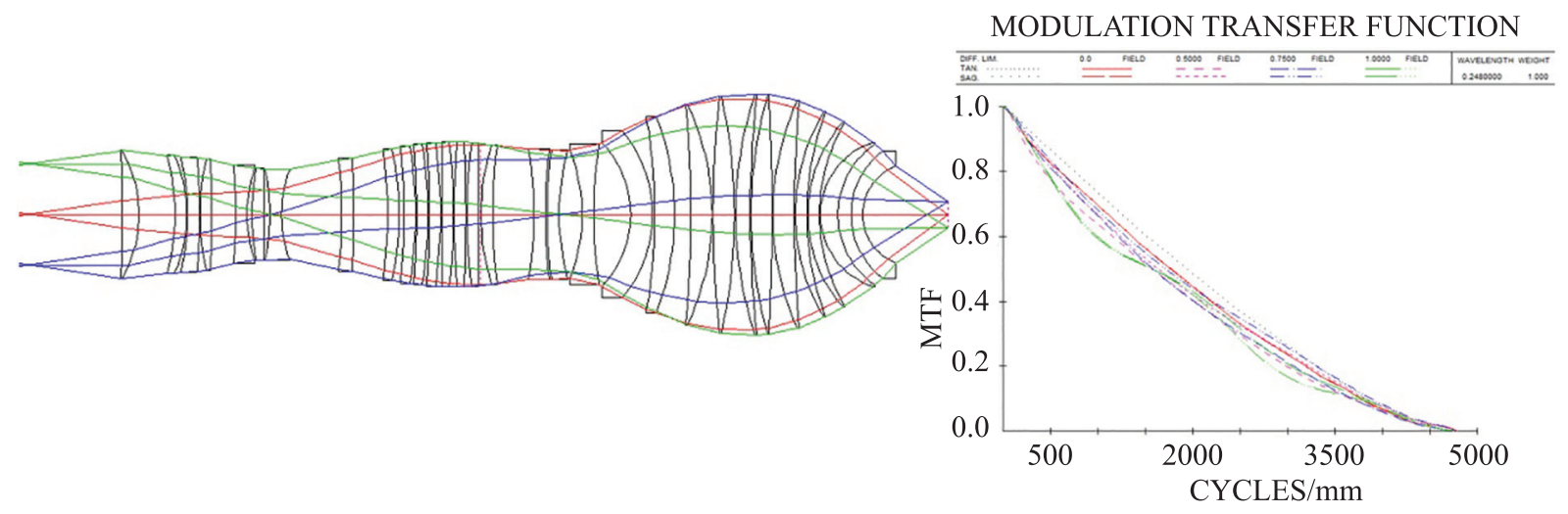

Fig. 8. Starting point of DUV lithographic objective with MTF

Moreover, the resulting starting point trapped in poor local minimum could be a consequence of the fact that usually DUV projection lenses [19] require aspheric surfaces with additional optimization complexity in design, while we construct the starting points only by standard surfaces. To meet the objective - diffraction limited system, in the next steps we inserted two more lenses and 6 aspheric surfaces of the high $6^{\text {th }}$ order running the further optimization by global optimization features with all 149 variables.

Table 2. Optical characteristics of obtained starting point for DUV lithographic objective

\begin{tabular}{l|l}
\hline Wavelength & $248 \mathrm{~nm}$ \\
\hline Numerical aperture & 0.6 \\
\hline Image height & $26 \mathrm{~mm}$ \\
\hline Magnification & -0.25 \\
\hline Total track length & $850 \mathrm{~mm}$ \\
\hline Front working distance & $95 \mathrm{~mm}$ \\
\hline Real distortion & $100 \mathrm{~nm}$ \\
\hline
\end{tabular}

The inserted lenses (yellow color) and aspherics surfaces (red color) are presented in Fig. 9. The resulting DUV lithographic objective with 32 lenses (Fig. 9) was optimized to meet design requirements for $350 \mathrm{~nm}$ microlithography, with RMS wave front aberrations of $6.88 \mathrm{~m} \lambda$. The characteristics of designed DUV lithographic objective are presented in Table 2.

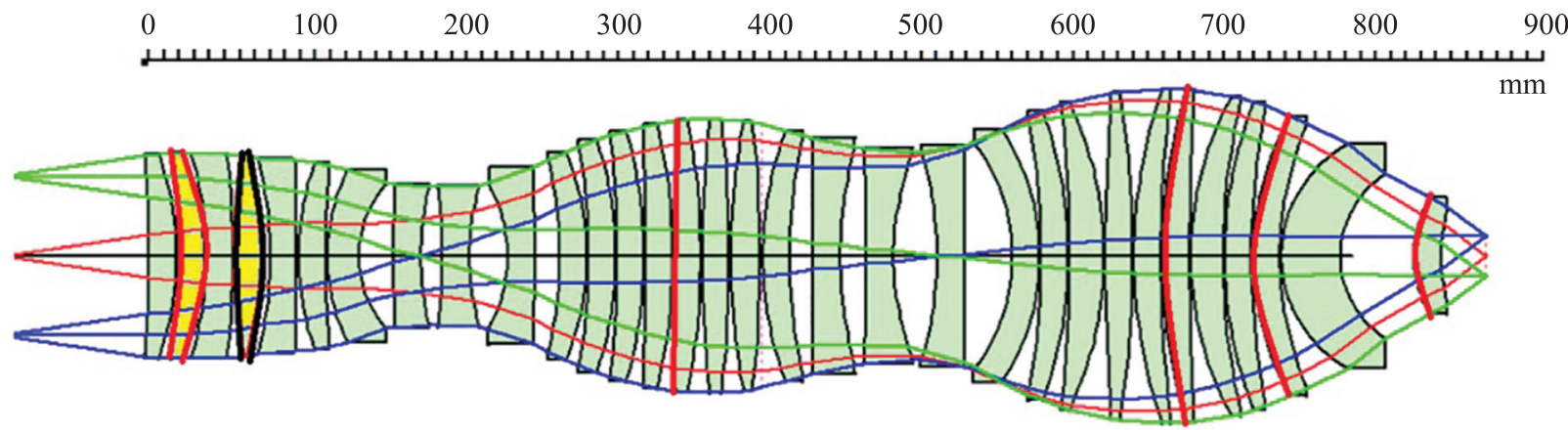

Fig. 9. Designed DUV lithographic objective with aspheric surfaces

Therefore, we can conclude that effectiveness of DSearch algorithm and developed method is proved even in constructing of DUV lithographic objective with significant complexity of design requirements

\section{Conclusions}

In this study, we presented a design approach for constructing starting points of lithographic objectives by applying global search algorithm. The significant complexity of projection lenses for lithography were reduced to 
moderate complexity of modules adjustable to input parameters of global search algorithm able to deal with adjusted inputs and boundaries. We explained the developed method and applied criteria in selecting the feasible starting points by density map of generated staring points. The effectiveness and feasibility of global search algorithms is proved by constructing starting design of projection lenses for 365 and $248 \mathrm{~nm}$ lithography. We found that, even when running simulation with few points of field and working wavelengths, we could design the projection lenses for lithography applying all required constraints (e.g. distortion, telecentricity).

The presented method and research make it feasible to apply DSearch algorithm to any lens design with significant complexity and similar requirements. The modern automated lens design is present and future of optical design based on implemented and applicable novel algorithms.

\section{Литература}

1. Bociort F., Van Turnhout M. Looking for order in the optical design landscape // Proceedings of SPIE. 2006. V. 6288. P. 628806. doi: 10.1117/12.681541

2. Qin H., Wan Y., Zhang W. Particle swarm optimization for automatic optical design in engineering optics // Jisuan Wuli, Chinese Journal of Computational Physics. 2011. V. 28. P. $433-$ 437.

3. Ulrich W., Rostalski H.J., Hudyma R. Development of dioptric projection lenses for deep ultraviolet lithography at Carl Zeiss // Journal of Microlithography, Microfabrication and Microsystems. 2004. V. 3. N 1. P. 87-96. doi: 10.1117/1.1637592

4. Dodoc A., Ulrich W., Feldmann H. Method of manufacturing projection objectives and set of projection objectives manufactured by that method. Patent US 20070013882. 2007.

5. Cao Z., Li Y., Mao Sh. Grouping design method of catadioptric projection objective for deep ultraviolet lithography // Optical Engineering. 2017. V. 56. N 2. P. 025102. doi 10.1117/1.OE.56.2.025102

6. Zoric N., Livshits I., Dilworth D., Okishev S. Design of an ultraviolet projection lens by using a global search algorithm and computer optimization // Advanced Optical Technologies. 2017. V. 6. N 1. P. 31-38. doi: 10.1515/aot-2016-0058

7. Dilworth D.C. The Ascendency of Numerical Methods in Lens Design // Journal of Imaging. 2018. V. 4. N 12. P. 137. doi: 10.3390/jimaging4120137

8. Livshits I.L., Sal'nikov A.V., Cho U. Choosing the starting system for designing objectives // Journal of Optical Technology. 2007. V. 74. N 11. P. 783-786. doi: 10.1364/JOT.74.000783

9. Зорич Н.Д., Лившиц И.Л., Окишев С.Г., Сомова Е.А., Анитропов Р.В., Летуновская М.В. Метод проектирования сложных объективов по частям // Научно-технический вестник информационных технологий, механики и оптики. 2017. Т. 17. № 2. C. 232-241. doi: 10.17586/2226-1494-2017-17-2-234-241

10. Harriott L.R. Limits of lithography // Proceedings of the IEEE. 2001. V. 89. N 3. P. 366-374. doi: 10.1109/5.915379

11. Bentley J., Olson C., Youngworth R.N. In the era of global optimization, the understanding of aberrations remains the key to designing superior optical systems // Proceedings of SPIE. 2010. V. 7849. P. 78490C. doi: 10.1117/12.871720

12. Levinson H.J. Principles of Lithography. $2^{\text {nd }}$ ed. Bellingham, WA: SPIE Press, 2005. P. 33-43.

13. Rothschild M. Projection optical lithography // Materials Today. 2005. V. 8. N 2. P. 18-24. doi: 10.1016/S1369-7021(05)00698-X

14. Dilworth D.C., Shafer D. Man versus Machine: a Lens Design Challenge // Proceedings of SPIE. 2013. V. 8841. P. 88410G. doi: 10.1117/12.2022871

15. Livshits I.L., Zoric N. A Concept of Ultraviolet Lithography System and Design of its Rear Part using Artificial Intelligence for Starting Design // Proc. $4^{\text {th }}$ International Conference on Photonics, Optics and Laser Technology. 2016. P. 82-86. doi: 10.5220/0005688500820086

16. Hooker J.N., Cagan J., Grossman I.E. Combining artificial intelligence and optimization in engineering design. Carnegie Mellon University, Tepper School of Business, 1994. P. 11-12.

17. Livshits I.L., Bronchtein I.G., Vasiliev V.N. Information technologies in CAD system for lens design // Proceedings of SPIE. 2009. V. 7506. P. 75060C. doi: 10.1117/12.837544

18. Thibault S., Gauvin J., Doucet M., Wang M. Enhanced optical design by distortion control // Proceedings of SPIE. 2005. V. 5962. P. 596211. doi: 10.1117/12.625151

\section{References}

1. Bociort F., Van Turnhout M. Looking for order in the optical design landscape. Proceedings of SPIE, 2006, vol. 6288, pp. 628806. doi: 10.1117/12.681541

2. Qin H., Wan Y., Zhang W. Particle swarm optimization for automatic optical design in engineering optics. Jisuan Wuli, Chinese Journal of Computational Physics, 2011, vol. 28, pp. 433-437.

3. Ulrich W., Rostalski H.J., Hudyma R. Development of dioptric projection lenses for deep ultraviolet lithography at Carl Zeiss. Journal of Microlithography, Microfabrication and Microsystems, 2004, vol. 3, no. 1, pp. 87-96. doi: $10.1117 / 1.1637592$

4. Dodoc A., Ulrich W., Feldmann H. Method of manufacturing projection objectives and set of projection objectives manufactured by that method. Patent US 20070013882, 2007.

5. Cao Z., Li Y., Mao Sh. Grouping design method of catadioptric projection objective for deep ultraviolet lithography. Optical Engineering, 2017, vol. 56, no. 2, pp. 025102. doi: 10.1117/1.OE.56.2.025102

6. Zoric N., Livshits I., Dilworth D., Okishev S. Design of an ultraviolet projection lens by using a global search algorithm and computer optimization. Advanced Optical Technologies, 2017, vol. 6, no. 1, pp. 31-38. doi: 10.1515/aot-2016-0058

7. Dilworth D.C. The Ascendency of Numerical Methods in Lens Design. Journal of Imaging, 2018, vol. 4, no. 12, pp. 137. doi: 10.3390/jimaging4120137

8. Livshits I.L., Sal'nikov A.V., Cho U. Choosing the starting system for designing objectives. Journal of Optical Technology, 2007, vol. 74, no. 11, pp. 783-786. doi: 10.1364/JOT.74.000783

9. Zoric N.D., Livshits I.L., Okishev S.G., Somova E.A.,Anitropov R.V., Letunovskaya M. V. Design method for complex lenses by dividing them into parts. Scientific and Technical Journal of Information Technologies, Mechanics and Optics, 2017, vol. 17, no. 2, pp. 232 241. (in Russian). doi: 10.17586/2226-1494-2017-17-2-234-241

10. Harriott L.R. Limits of lithography. Proceedings of the IEEE, 2001, vol. 89, no. 3, pp. 366-374. doi: 10.1109/5.915379

11. Bentley J., Olson C., Youngworth R.N. In the era of global optimization, the understanding of aberrations remains the key to designing superior optical systems. Proceedings of SPIE, 2010, vol. 7849 , pp. 78490 C. doi: 10.1117/12.871720

12. Levinson H.J. Principles of Lithography. $2^{\text {nd }}$ ed. Bellingham, WA, SPIE Press, 2005, pp. 33-43.

13. Rothschild M. Projection optical lithography. Materials Today, 2005, vol. 8, no. 2, pp. 18-24. doi: 10.1016/S1369-7021(05)00698-X

14. Dilworth D.C., Shafer D. Man versus Machine: a Lens Design Challenge. Proceedings of SPIE, 2013, vol. 8841, pp. 88410G. doi: $10.1117 / 12.2022871$

15. Livshits I.L., Zoric N. A Concept of Ultraviolet Lithography System and Design of its Rear Part using Artificial Intelligence for Starting Design. Proc. $4^{\text {th }}$ International Conference on Photonics, Optics and Laser Technology, 2016, pp. 82-86. doi: 10.5220/0005688500820086

16. Hooker J.N., Cagan J., Grossman I.E. Combining artificial intelligence and optimization in engineering design. Carnegie Mellon University, Tepper School of Business, 1994, pp. 11-12.

17. Livshits I.L., Bronchtein I.G., Vasiliev V.N. Information technologies in CAD system for lens design. Proceedings of SPIE, 2009, vol. 7506, pp. 75060C. doi: 10.1117/12.837544

18. Thibault S., Gauvin J., Doucet M., Wang M. Enhanced optical design by distortion control. Proceedings of SPIE, 2005, vol. 5962, pp. 596211. doi: 10.1117/12.625151 
19. Mack C. Fundamental Principles of Optical Lithography: The Science of Microfabrication. New York: John Wiley and Sons, 2007. P. 190-194. doi: 10.1002/9780470723876

\section{Авторы}

Зорич Нэнад Джуро - аспирант, Университет ИТМО, СанктПетербург, 197101, Российская Федерация, Scopus ID: 55614032300 , ORCID ID: 0000-0001-9408-277X, nenadnex@gmail.com

Смирнова Ирина Геннадьевна - кандидат технических наук, доцент, Университет ИТМО, Санкт-Петербург, 197101, Российская Федерация, Scopus ID: 57195684395, ORCID ID: 0000-0001-8357-3987,igsmirnova@itmo.ru

Георгиу Стефанос - магистр, аспирант, научный исследователь, Афинский университет экономики и бизнеса, Афины, 10431 Греция, Scopus ID: 56988937100, ORCID ID: 0000-0002-3508-3163, sgeorgiou@aueb.gr
19. Mack C. Fundamental Principles of Optical Lithography: The Science of Microfabrication. New York, John Wiley and Sons, 2007, pp. 190-194. doi: 10.1002/9780470723876

\section{Authors}

Nenad D. Zoric — postgraduate, ITMO University, Saint Petersburg, 197101, Russian Federation, Scopus ID: 55614032300, ORCID ID: 0000-0001-9408-277X, nenadnex@gmail.com

Irina G. Smirnova - PhD, Associate Professor, ITMO University, Saint Petersburg, 197101, Russian Federation, Scopus ID: 57195684395, ORCID ID: 0000-0001-8357-3987,igsmirnova@itmo.ru

Stefanos Georgiou - master of science, postgraduate, Researcher, Athens University of Economics and Business, Athens, 10431, Greece, Scopus ID: 56988937100, ORCID ID: 0000-0002-3508-3163, sgeorgiou@aueb.gr 